\title{
The Role of the Plant Nucleolus in Pre-mRNA Processing
}

\author{
J.W.S. Brown(®), P.J. Shaw
}

\begin{abstract}
Contents

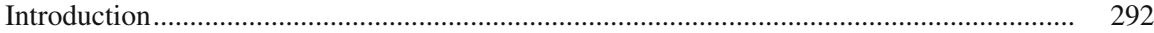

The Dynamic Nucleus............................................................................................ 292

Nuclear Bodies in Animal Cells ..................................................................................... 293

Nuclear Bodies in Plant Cells ................................................................................. 294

Traditional Functions of the Nucleolus.......................................................................... 295

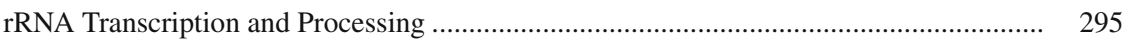

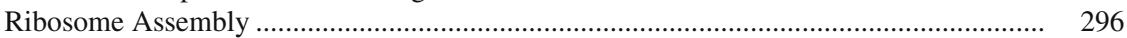

Other Functions of the Nucleolus in RNA Metabolism........................................................ 297

Signal Recognition Particle............................................................................................ 297

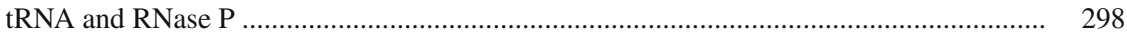

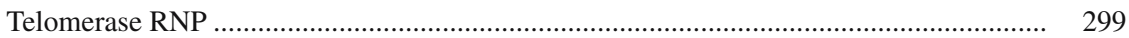

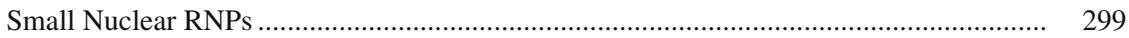

Heterochromatic Small Interfering RNAs ................................................................ 299

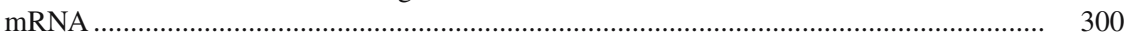

The Nucleolus as a Major Centre for RNA Metabolism

and Regulation of Gene Expression .....................................................................

Abstract The nucleolus is a multifunctional compartment of the eukaryotic nucleus. Besides its well-recognised role in transcription and processing of ribosomal RNA and the assembly of ribosomal subunits, the nucleolus has functions in the processing and assembly of a variety of RNPs and is involved in cell cycle control and senescence and as a sensor of stress. Historically, nucleoli have been tenuously linked to the biogenesis and, in particular, export of mRNAs in yeast and mammalian cells. Recently, data from plants have extended the functions in which the plant nucleolus is involved to include transcriptional gene silencing as well as mRNA surveillance and nonsense-mediated decay, and mRNA export. The nucleolus in plants may therefore have important roles in the biogenesis and quality control of mRNAs.
\end{abstract}

\footnotetext{
J.W.S. Brown

Plant Sciences Division, College of Life Sciences, University of Dundee at SCRI, Invergowrie, Dundee DD2 5DA, Scotland, UK

e-mail: john.brown@scri.ac.uk
} 


\section{Introduction}

The nucleolus is the largest and most visible sub-nuclear compartment. Its main function is the transcription and processing of ribosomal RNA (rRNA) and ribosomal subunit production. In recent years, molecular and proteomic approaches have begun to dissect the pathways of ribosomal subunit assembly and transport from the nucleolus and examine the composition of protein complexes and RNPs involved in these processes (Grandi et al. 2002; Dragon et al. 2002; Schafer et al. 2003; Gallagher et al. 2004; Grannemann and Baserga 2004, 2005). In addition, many lines of evidence point to the nucleolus having a wide range of other functions in both RNA metabolism and cell growth (for reviews see Pederson 1998; Olsen et al. 2000; Olsen 2004; Raška et al. 2006; Boisvert et al. 2007). The multifunctional nature of the nucleolus has also been highlighted by proteomic approaches which have identified numerous unexpected proteins in the nucleolus, indicative of new interactions or functions (Andersen et al. 2002, 2005; Scherl et al. 2002; Pendle et al. 2005). The presence of non-ribosomal RNAs such as the RNA moieties of the signal recognition particle (SRP) and telomerase and some tRNAs suggests roles in processing and assembly of other RNAs and RNPs (Pederson 1998; Olsen et al. 2000; Olsen 2004; Boisvert et al. 2007). In this aspect, plants are of growing importance through the recent linking of the nucleolus to production of heterochromatic siRNAs and transcriptional gene silencing (Li et al. 2006; Pontes et al. 2006) and to mRNA export, mRNA surveillance and nonsense-mediated decay (Kim et al., unpublished). Finally, the nucleolus has been shown to be crucial to cell division regulation and senescence and as a sensor of cell stress (Rubbi and Milner 2003; Olsen 2004; Boisvert et al. 2007). In this chapter, we examine the multifunctionality of the eukaryotic nucleolus and describe recent data on novel functions of the plant nucleolus and, in particular, its potential roles in mRNA processing and biogenesis.

\section{The Dynamic Nucleus}

The nucleus is the defining eukaryotic organelle. It is highly organised, with chromatin regions containing the genomic DNA and inter-chromatin domains containing the machinery for gene expression and regulation processes (Misteli 2005). The nucleus contains many sub-nuclear structures or bodies that vary in their components and functions (Lamond and Spector 2003; Cioce and Lamond 2005; Misteli 2005; Handwerger and Gall 2006). Such structures, rather than being fixed, unchanging entities, reflect the accumulation and steady-state flux of sub-populations of molecules and complexes, as has been clearly shown by fluorescence recovery after photobleaching (FRAP) studies. Their dynamic nature is also demonstrated by changes in size and distribution under different conditions and during differentiation and development reflecting the high mobility and trafficking of many components between the different bodies and nucleoplasm (Boudonck et al. 1998, 1999; Lamond and Spector 2003; Cioce and Lamond 2005; Misteli 2005; Handwerger and Gall 2006; Gorski et al. 2006; Raška et al. 2006). Although the functions of 
many nuclear bodies have yet to be fully elucidated, clearly some nuclear bodies have multiple functions and some functions may overlap. Thus the spatial and temporal organisation of the nucleus is highly dynamic and is integral to the regulation and integration of networks of gene expression processes which ultimately determine cellular function. Consistent with these considerations, the nucleolus, already recognised as multifunctional, continues to add to its list of functions and emerges as a dynamic and major centre for RNA metabolism in the cell.

\section{Nuclear Bodies in Animal Cells}

The nucleolus is not membrane-bound, has a high relative refractive index and thus appears under phase contrast microscopy as a dense region of the nucleus. It is formed around tens, hundreds or even thousands of tandemly repeated ribosomal RNA (rRNA) gene units and contains rRNA transcripts at different stages of transcription, processing and assembly into ribosomal subunits and the multitude of RNAs and proteins required for these processes. The observed nucleolar compartment therefore represents a snapshot of the steady-state import of components and export of the major products, the ribosomal subunits (Leung and Lamond 2003; Cheutin et al. 2004). The fundamental role of the nucleolus in production of ribosomes needed for translation is also reflected in the effects on rRNA transcription, ribosome production and nucleolar morphology of cell growth and environmental conditions (Leung and Lamond 2003; Leung et al. 2004; Mosgoeller 2004; Dove et al. 2006; Raška et al. 2006). This integral link between the nucleolus and normal functioning of the cell is further highlighted by its involvement in cell division, cell death and stress responses (Rubbi and Milner 2003; Olsen 2004; Raška et al. 2006; Boisvert et al. 2007). In addition to the factors required for ribosome biogenesis, the nucleolus also functions in aspects of the biogenesis of many other RNP complexes and contains proteins and protein complexes involved in a range of cellular functions as detailed below in this review.

Besides the nucleolus, other nuclear bodies such as Cajal bodies (CBs) and speckles have been identified in animal and plant nuclei (Cioce and Lamond 2005; Handwerger and Gall 2006). In particular, CBs, which are often closely associated with nucleoli, contain a number of different proteins including coilin, a protein essential for CB formation, and fibrillarin and dyskerin, nucleolar proteins required for pre-rRNA processing and modification (Cioce and Lamond 2005). CBs are involved in the maturation of spliceosomal snRNPs and snoRNPs, with newly assembled snRNPs and snoRNPs trafficking through CBs before accumulating in splicing speckles and the nucleolus, respectively (Narayanan et al. 1999; Sleeman and Lamond 1999). The modification of specific nucleotides in snRNAs, guided by small CB-specific RNAs (scaRNAs), occurs in CBs (Darzacq et al. 2002; Jady et al. 2003). CBs also contain U7snRNA, which functions in the $3^{\prime}$ end processing of some histone mRNAs, and are enriched in the RNA of telomerase RNP (Frey and Matera 1995; Jady et al. 2004; Zhu et al. 2004; Pillai et al. 2005). CBs are dynamic structures whose presence and abundance are linked 
to the transcriptional activity of the cell and their association with the nucleolus is reflected in the trafficking of nucleolar proteins between the nucleolus and CBs. Thus nucleoli and CBs are both multifunctional and involved in RNP maturation.

\section{Nuclear Bodies in Plant Cells}

In plants, the best-characterised nuclear bodies are the nucleolus and CBs. The plant nucleolus differs to some extent in organisation and structure from the animal nucleolus, although its major function in rRNA and ribosomal subunit production remains the same (Brown and Shaw 1998; Shaw and Brown 2004). The plant nucleolus contains a large proportion of dense fibrillar component (DFC), much more than in typical animal nucleoli, which is surrounded by the granular component (GC) (Fig. 1). The DFC regions contain rDNA transcription units which are being actively transcribed and have been visualised as 'Christmas tree' structures around $300 \mathrm{~nm}$ in length (Shaw and Jordan 1995; Gonzalez-Melendi and Shaw 2001). The localisation by fluorescence microscopy and in situ hybridisation of nucleolar proteins, rRNA gene regions and snoRNA species to sub-domains within plant nucleoli have been correlated with early and late events in rRNA processing (Beven et al. 1996; Brown and Shaw 1998). A distinctive feature of most plant nucleoli is the nucleolar cavity, whose function is unknown but contains spliceosomal snRNAs and accumulates snoRNAs (Beven et al. 1995, 1996) and contains centres for the production of heterochromatic small interfering RNAs (siRNAs) (Pontes et al. 2006). The relationship between these centres and CBs is not yet clear (Li et al. 2006; Pontes et al. 2006) but highlights the interaction between CBs and the nucleolus.

Plant CBs vary in number and size in different cells and under different conditions (Boudonck et al. 1998; Collier et al. 2006). Recently, plant coilin was identified and, despite the sequence divergence from animal coilin, was shown to be required for $\mathrm{CB}$ formation. Mutants in plant coilin will be invaluable in addressing the functions

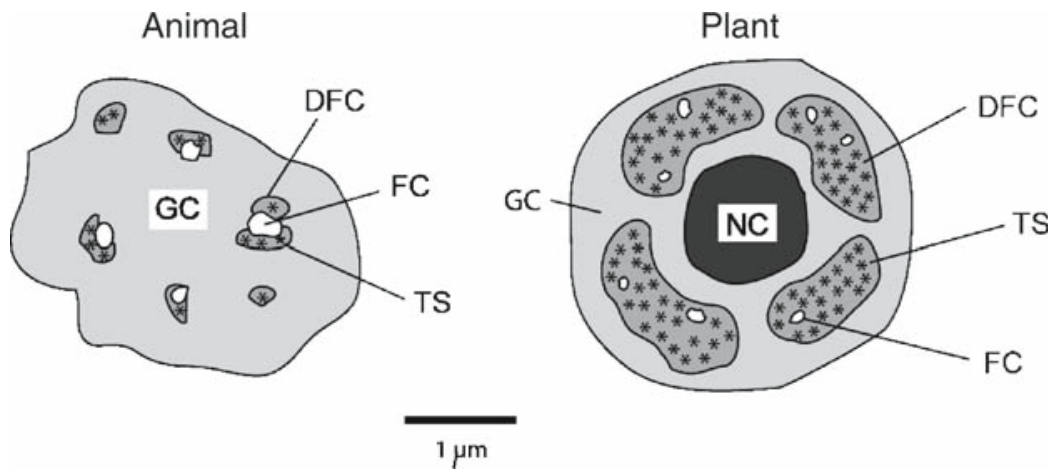

Fig. 1 Comparison of the structure of animal and plant nucleoli. $T S$, transcription sites; $F C$, fibrillar centres; $D F C$, dense fibrillar component; $G C$, granular component; $N C$, nucleolar cavity. 
and properties of plant CBs (Collier et al. 2006). Plant CBs also contain snRNAs, snoRNAs and fibrillarin (Beven et al. 1995, 1996; Brown and Shaw 1998) and plant scaRNAs have been identified consistent with conserved roles in snRNP and snoRNP maturation (Marker et al. 2002). Moreover, the majority of plant snoRNAs are organised in gene clusters and expressed as polycistronic precursor snoRNAs (Brown et al. 2003). The detection of these polycistronic precursors in CBs and the nucleolus by in situ hybridisation suggests that processing occurs in both locations and/or that pre-snoRNAs traffic to the nucleolus via CBs (Shaw et al. 1998). The nucleolus is also involved in some virus infections (both animal and plant), with particular viral proteins localising to the nucleolus (Hiscox 2002, 2007). Although the function of the nucleolar localisation of many of these proteins remains to be established, the nucleolar accumulation of the ORF3 protein of the plant virus groundnut rosette virus (GRV) has been shown to involve interactions with CBs and fibrillarin and is essential for the formation of cytoplasmic RNPs and long-distance virus movement (Kim et al. 2007a, b). Finally, the Arabidopsis nucleolus contains exon junction complex proteins, involved in linking transcription and splicing to translation, export and mRNA surveillance (Pendle et al. 2005). Thus new functions in RNA metabolism have been demonstrated for both plant CBs and the nucleolus.

Other nuclear bodies in plants have been defined by the presence of particular proteins such as splicing factors (see the chapter by G. S. Ali and A. S. N. Reddy, this volume) and cyclophilins, HYL1, phytochrome and AKIP1. At present, the components and functions of these bodies are not well characterised but SR proteins and cyclophilins are found in distinct splicing speckles and cyclophilin-containing bodies can interact and regulate functions in splicing (Lorković 2004). HYL1, involved in microRNA biogenesis, localises to a small number of nuclear bodies while phytochrome- and AKIP-containing bodies are involved in signalling pathways interactions and may regulate mRNAs at the transcriptional or post-transcriptional levels (Yamaguchi et al. 1999; Han et al. 2002; Kircher et al. 2002; Chen et al. 2003; Ang et al. 1998; Li et al. 2002; Shaw and Brown 2004; Song et al. 2007). Thus nuclear bodies are sites where different factors accumulate, allowing efficient RNA-protein and protein-protein interactions or RNP assembly, to influence or regulate a particular process. The bodies can form or dissemble or increase and decrease in size and number depending on different conditions or activity of the cell, again reflecting the dynamic interplay between nuclear bodies and the surrounding nucleoplasm.

\section{Traditional Functions of the Nucleolus}

\section{rRNA Transcription and Processing}

The major recognised function of the nucleolus is transcription and processing of ribosomal RNA and assembly of ribosomal subunits. Eukaryotic ribosomal RNA genes are organised in large clusters, often containing hundreds or thousands of repeated genes, with each gene encoding one copy of the $18 \mathrm{~S}, 5.8 \mathrm{~S}$ and $25-28 \mathrm{~S}$ 
rRNAs. The coding regions are separated by internal transcribed spacer (ITS) regions and flanked by external transcribed spacer (ETS) regions. Genes are transcribed by RNA polymerase I as polycistronic precursor rRNAs which are processed to the mature 5.8S, $18 \mathrm{~S}$ and 25-28S rRNAs. Processing of pre-rRNAs involves (a) cleavage of the transcript into precursors of the mature rRNAs and trimming of these precursors to their final size and (b) modification of specific rRNA nucleotides. The best-characterised pathway of pre-rRNA processing is that of yeast, in which the step-wise cleavage and trimming reactions required for production of mature rRNAs have been demonstrated and in which many of the protein and snoRNP components involved have been identified (Venema and Tollervey 1999; Fatica and Tollervey 2002). Initial cleavage of the pre-rRNA involves the U3, U14, MRP, snR10 and snR30 snoRNAs and the resultant precursors are trimmed by the action of exonucleases: Rat1p, Xrn1p and the exosome (Venema and Tollervey 1999; Fatica and Tollervey 2002). The pathway of processing and modification is poorly understood in plants but is likely to contain many processing steps which are conserved with other eukaryotes. Nevertheless, significant advances in understanding rRNA processing and the function of nucleolar proteins have been made recently. In particular, a multiprotein complex containing nucleolin, fibrillarin, U3 and U14 has been shown to cleave the pre-rRNA in the 5' external transcribed sequence (Saez-Vasquez et al. 2004). In addition, the absence of nucleolin expression causes disruption of the structural organisation of the nucleolus (Pontvianne et al. 2007).

Ribosomal RNAs contain numerous nucleotide modifications. The two major modifications in rRNA are 2 '- $O$-ribose methylation and pseudouridylation. The sites of modification are determined by regions of complementarity to their cognate rRNA sequences. Box $\mathrm{C} / \mathrm{D}$ and box $\mathrm{H} / \mathrm{ACA}$ snoRNAs are responsible for generating $2^{\prime}$-O-ribose methylation and pseudouridylation of nucleotides, respectively (Kiss 2002). Thus snoRNAs act as guide sequences to define which nucleotides in rRNA are modified. In Arabidopsis and rice, snoRNA genes have been identified by both bioinformatics predictions and experimental approaches (Barneche et al. 2001; Brown et al. 2001, 2003; Qu et al. 2001; Marker et al. 2002). Many of the plant snoRNAs are conserved in yeast and/or human, in terms of the rRNA target sequences which are modified, but there are a number of plant-specific snoRNAs guiding modification of nucleotides in plant rRNAs which are unmodified in other organisms (Barneche et al. 2001; Brown et al. 2001; Qu et al. 2001; Marker et al. 2002). The fact that so many nucleotide modifications are conserved in eukaryotic rRNAs suggests important functions in rRNA processing or ribosome activity. The majority of nucleotide modifications are in the active sites of the ribosome and are thought to influence the efficiency of the ribosome and protein translation (Decatur and Fournier 2002).

\section{Ribosome Assembly}

The eukaryotic ribosome consists of a small (40S) and a large (60S) subunit containing the $5 \mathrm{~S}, 5.8 \mathrm{~S}, 18 \mathrm{~S}$ and $26-28 \mathrm{~S}$ rRNAs associated with around 80 ribosomal 
proteins (Tate and Poole 2004). As with other large RNP complexes such as the spliceosome, correct assembly occurs in a regulated and co-ordinated step-wise pathway involving non-ribosome factors and ribosomal proteins required for correct rRNA folding, protein association and ultimately export of the ribosomal subunits through the nuclear pore complex to the cytoplasm (Venema and Tollervey 1999; Fatica and Tollervey 2002; Grannemann and Baserga 2004). The pre-rRNA transcript is assembled into a $90 \mathrm{~S}$ pre-ribosome containing factors required for formation of both ribosomal subunits. Cleavage of the primary transcript gives rise to pre-ribosomes which with further processing and assembly produce the 40S and 60S ribosomal subunits (Fatica and Tollervey 2002; Grannemann and Baserga 2004). One of these pre-ribosomal complexes includes the small subunit (SSU) processosome which contains the U3snoRNP along with ribosomal and nonribosomal proteins including novel Utp proteins (Dragon et al. 2002; Grandi et al. 2002; Schafer et al. 2003). The SSU processosome complex is thought to be the RNP complex previously observed as knobs at the 5' regions of pre-rRNA transcripts (Miller and Beatty 1969). In plants, very little is known about ribosomal subunit assembly apart from detailed analyses of the ribosomal protein complement (Barakat et al. 2001) and the identification of orthologues of some yeast and human associated factors by, for example, nucleolar proteomics (Pendle et al. 2005). Thus the biochemistry of rRNA processing and ribosome assembly lags significantly behind that of yeast and animal systems.

\section{Other Functions of the Nucleolus in RNA Metabolism}

Evidence for the nucleolus having functions other than rRNA transcription/processing and ribosome assembly continues to increase. These functions can be grouped into RNA processing activities, often associated with RNP assembly, mRNA metabolism, and regulatory cellular functions such as the control of the cell cycle and cell aging and as a sensor of cell stress (Fig. 2). In many cases, evidence currently comes from only one organism, making extrapolation to a general nucleolar function difficult. Nevertheless, the novel functions illustrate the potential complexity of the nucleolus. The various functions of the nucleolus have been reviewed previously (Pederson 1999; Olsen 2004; Boisvert et al. 2007) and here we briefly describe the roles of the nucleolus in RNA processing and RNP assembly.

\section{Signal Recognition Particle}

The signal recognition particle (SRP) is a small RNP involved in targeting the translation of specific proteins to the endoplasmic reticulum. SRP consists of the SRP RNA associated with specific proteins (Walter and Johnson 1994). At least part of the assembly of the SRP has been shown to occur in the nucleolus. Most, but not all, of the protein components of the mature cytoplasmic SRP (SRP19, 


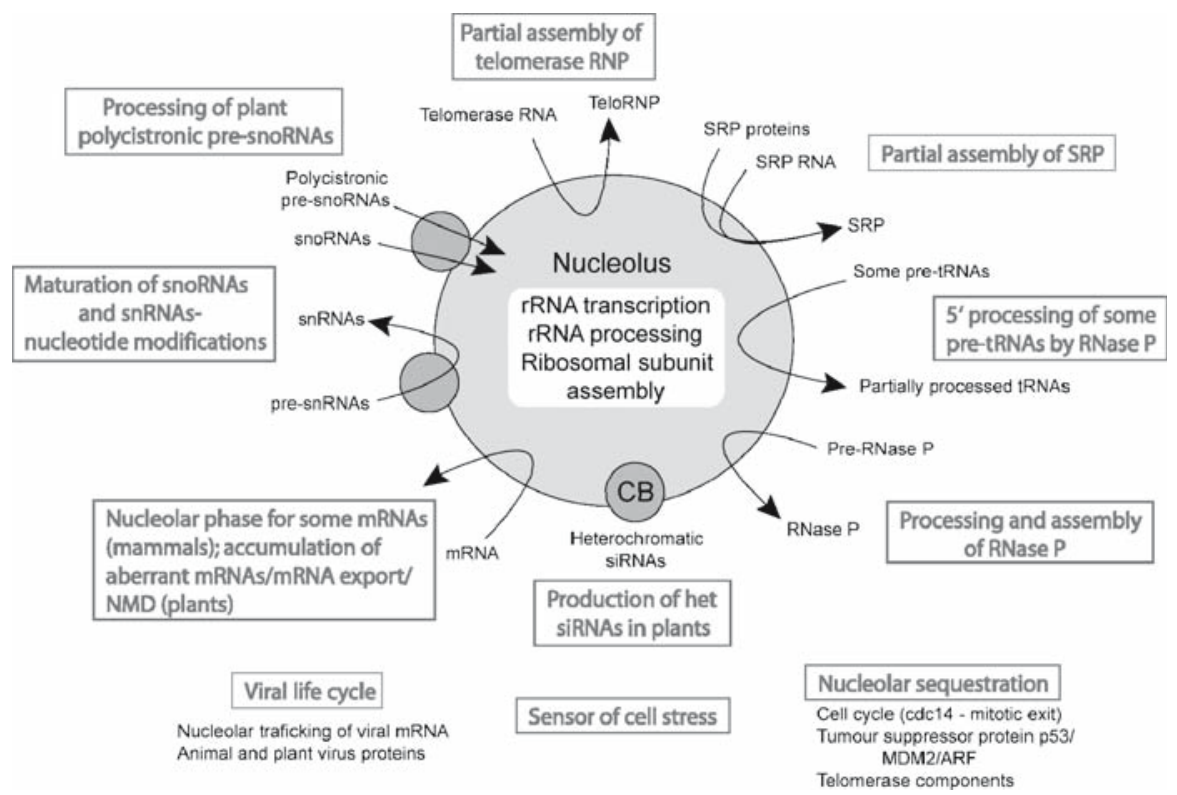

Fig. 2 The multifunctional nucleolus. Functions of the nucleolus and associated Cajal bodies in RNA metabolism and cell processes.

SRP68 and SRP72 but not SRP54) have been localised to the nucleolus in vertebrates (Politz et al. 2000) and in yeast (Grosshans et al. 2001). SRP RNA injected into mammalian cultured cells rapidly localised to the nucleolus and then gradually relocated to the cytoplasm, suggesting that SRP was being assembled in the nucleolus and then exported (Jacobsen and Pederson 1998). Thus the assembly of the SRP has a nucleolar phase, but must be completed in the cytoplasm.

\section{tRNA and RNase P}

Precursor tRNAs have been detected in the nucleolus by in situ hybridisation (Bertrand et al. 1998). Pre-tRNAs are trimmed at $5^{\prime}$ and $3^{\prime}$ ends and undergo base modifications such as pseudouridylation and $3^{\prime}$ end processing (Hopper and Phizicky 2003). The $5^{\prime}$ trimming of pre-tRNAs is catalysed by RNase $\mathrm{P}$ and both protein and RNA components of this RNP have been localised to the nucleolus (Jacobson et al. 1997; Jarrous et al. 1999), as has Cbf5p/Dyskerin which catalyses these and other pseudouridylations. The presence of components of the RNase P RNP also suggests that the assembly of this RNP could occur in the nucleolus. It has been shown that most tRNAs in S. cerevisiae are exported from the nucleus as aminoacyl tRNAs and that, in mutants defective in aminoacylation of tRNA, tRNAs accumulate in the nucleolus (Steiner-Mosonyi and Mangroo 2004), suggesting that the machinery for aminoacylation is also present in the nucleolus. 


\section{Telomerase RNP}

Chromosome replication in eukaryotes requires the addition of multiple tandem repeats of a short sequence at the ends of each chromosome (TTAGGG in humans). This is catalysed by a reverse transcriptase (TERT), which copies the repeated sequence from an associated RNA (TERC) (Cech 2004). Most somatic cells do not have active telomerase, which is proposed to limit the number of rounds of cell division that they can support and has been suggested to be a factor in aging and carcinogenesis (Maser and DePinho 2002). The localisation of the RNA and the reverse transcriptase catalytic subunit of human telomerase, hTERT, suggests that the telomerase RNP may be assembled in the nucleolus (Mitchell and Collins 2000; Etheridge et al. 2002). Telomerase RNA contains a box H/ACA domain and a CB localisation signal allowing the telomerase RNP to localise to both CBs and the nucleolus in its maturation (Mitchell et al. 1999; Lukowiak et al. 2001; Jady et al. 2004). The localisation of telomerase in the nucleolus may reflect its assembly pathway and/or its sequestration as part of the regulation of its activity. Telomerase resides in the nucleolus but is specifically redistributed in late S-phase, when telomere replication takes place, thereby avoiding inappropriate expression throughout the nucleus which could cause new telomeric structures to be nucleated on replication intermediates or double strand breaks (Wong et al. 2002).

\section{Small Nuclear RNPs}

Small nuclear RNAs (snRNAs) are involved in splicing and form the cores of the spliceosomal complexes. There is good evidence that U4/U6.U5 and U2 snRNAs are also in the nucleolus and undergo part of their maturation or assembly processing there, and that the individual snRNAs are transported independently to the nucleolus (Lange and Gerbi 2000; Yu et al. 2001; Gerbi and Lange 2002). A nucleolar phase for snRNPs is strongly supported by the proteomic analyses of the nucleoli in both human and plant cells (Andersen et al. 2002, 2005; Scherl et al. 2002; Pendle et al. 2005). These studies showed the presence of many snRNA-associated proteins, particularly the Sm class of proteins, pointing to a role in the maturation of snRNAs and the assembly of snRNPs. U6snRNA differs from the other spliceosomal snRNAs in its cap structure and maturation pathway. Factors involved in U6 nucleotide modifications are found in the nucleolus, suggesting a nucleolar phase for the production of mature U6snRNA (Ganot et al. 1999).

\section{Heterochromatic Small Interfering RNAs}

Plants contain a novel RNA polymerase (RNA polymerase IV, Pol IV) involved in production of transcripts which give rise to double-stranded RNAs and small interfering 
RNAs (siRNAs) which guide DNA methylation. The protein components required for the production of such heterochromatic siRNAs include the large subunit of Pol IV (NRPD1b), AGO3, DCL3 and RDR2. These proteins co-localised with siRNAs in foci in the nucleolus or in CBs (Li et al. 2006; Pontes et al. 2006). Thus the nucleolus/CBs are involved in siRNA production and assembly of silencing complexes. This role in the transcriptional gene silencing pathway in plants raises the question of whether other RNA silencing pathways or the cross talk among pathways also involves the nucleolus.

\section{$m R N A$}

The nucleolus has previously been implicated in mRNA export or surveillance (Schneiter et al. 1995; Pederson 1998). In yeast, in mRNA transport-defective mutants and mutants of some nucleolar proteins, the nucleolus was disrupted and fragmented and accumulated poly(A)+ RNA (Kadowaki et al. 1995; Schneiter et al. 1995). Similarly, in transport-defective mutants in Schizosaccharomyces pombe, an intron-containing transcript accumulated in the nucleolus, whereas transcripts from the intronless cDNA were exported (Ideue et al. 2004). Furthermore, heat shock of $S$. pombe cells resulted in accumulation of poly(A)+ RNA in the nucleolus (Tani et al. 1995) while ethanol stress caused the accumulation of specific transcripts in the nucleolus (Brodsky and Silver 2000). In S. pombe mutants which undergo aberrant cytokinesis generating nuclei with and without a nucleolus, poly $(\mathrm{A})+$ accumulated only in the latter, suggesting that poly $\mathrm{A}+$ mRNA associates transiently with the nucleolus during export (Ideue et al. 2004). However, recent work on mechanisms of RNA quality control which involve polyadenylation of aberrant RNA species by the TRAMP complex before their degradation may explain the accumulation of polyadenylated RNA species in some of the yeast mutants (Carneiro et al. 2007). In mammalian cells, some spliced mRNAs (e.g. $c-m y c$ ) were localised to the nucleolus while their unspliced versions were found in the nucleoplasm (Bond and Wold 1993). Finally, the nucleolar targeting of some animal viral proteins regulates viral mRNA export and is essential to the virus life cycle, being required for viral replication or diverting normal host cell functions (Hiscox 2002, 2007). Whether the nucleolus is directly involved in mRNA export is still an open question.

\section{mRNA Biogenesis Proteins in the Nucleolus}

Recent proteomic and RNomic analyses of nucleoli have again raised the question of the function of the nucleolus in mRNA biogenesis. Proteomics of human and plant nucleoli identified almost 700 and 217 proteins, respectively (Andersen et al. 2002, 2005; Scherl et al. 2002; Pendle et al. 2005; Leung et al. 2006). The plant proteome contained many expected nucleolar, ribosome biogenesis and ribosomal 
proteins as well as core snoRNP proteins and proteins involved in snoRNP biogenesis (Pendle et al. 2005). Unexpectedly, many components of mRNA splicing and translation were found in the plant nucleolus, an observation also made in the human nucleolar proteome (Andersen et al. 2002; Scherl et al. 2002). In particular, the plant nucleolar proteome contained exon junction complex (EJC) proteins which were also shown to be associated with nucleoli by localisation of GFP fusions (Pendle et al. 2005). In contrast, EJC proteins were detected in the human nucleolar proteome but have not been observed in the nucleolus (Custódio et al. 2004; Palacios et al. 2004), suggesting potential differences in EJC assembly, storage or function between animals and plants. The EJC is a multi-protein complex that is deposited upstream of splice junctions in mRNAs after intron splicing. It contains proteins that are recruited as part of the spliceosome, that interact with mRNP export adaptors, that enhance translation or that are involved in nonsensemediated decay (Stutz and Izzuralde 2003; Maquat 2004; Lejeune and Maquat 2005; Tange et al. 2004; Andersen et al. 2006). As such, EJC proteins link gene transcription with splicing, export, translation and nonsense-mediated decay (Fig. 3). The discovery of EJC proteins, as well as splicing and translation factors, associated with the plant nucleolus suggested that aspects of mRNA biogenesis in plants involve the nucleolus.

\section{mRNAs in the Plant Nucleolus}

Whether mRNAs are present in the plant nucleolus was addressed by sequencing clones from cDNA libraries made from cell cultures, isolated nuclei and purified nucleoli. Not only were mRNAs detected in the nucleolar cDNA library but the abundance of different classes of mRNAs was significantly different between the three libraries (Fig. 4; Kim et al., unpublished). The mRNAs fell into three classes: fully spliced transcripts, transcripts from single exon genes (i.e. that had not undergone splicing) and aberrantly spliced transcripts. Aberrantly spliced transcripts include transcripts with potential splicing errors, incompletely spliced transcripts (where one or more introns is unspliced) and alternatively spliced transcripts. Although it is difficult to distinguish among these possibilities, the aberrant nature of this class of the transcripts in the nucleolus was demonstrated by the fact that over $90 \%$ contained premature stop codons. The proportion of fully spliced transcripts decreased from $82 \%$ in the whole cell library to $68 \%$ and $42 \%$ in the nuclear and nucleolar libraries, respectively. In contrast, the proportion of aberrantly spliced transcripts increased from $2 \%$ in the whole cell library to $13 \%$ and $38 \%$ in the nuclear and nucleolar libraries, respectively, while those of single exon genes remained around the same levels (16\%-20\%) (Fig. 4; Kim et al., unpublished). Thus the nucleolus contained enhanced levels of aberrant mRNAs. The unexpected discovery of mRNAs in the nucleolus suggests that mRNAs can move freely between the nucleoplasm and nucleolus and may point to a nucleolar mRNA export function. The majority of aberrant mRNAs contained premature termination codons, further 


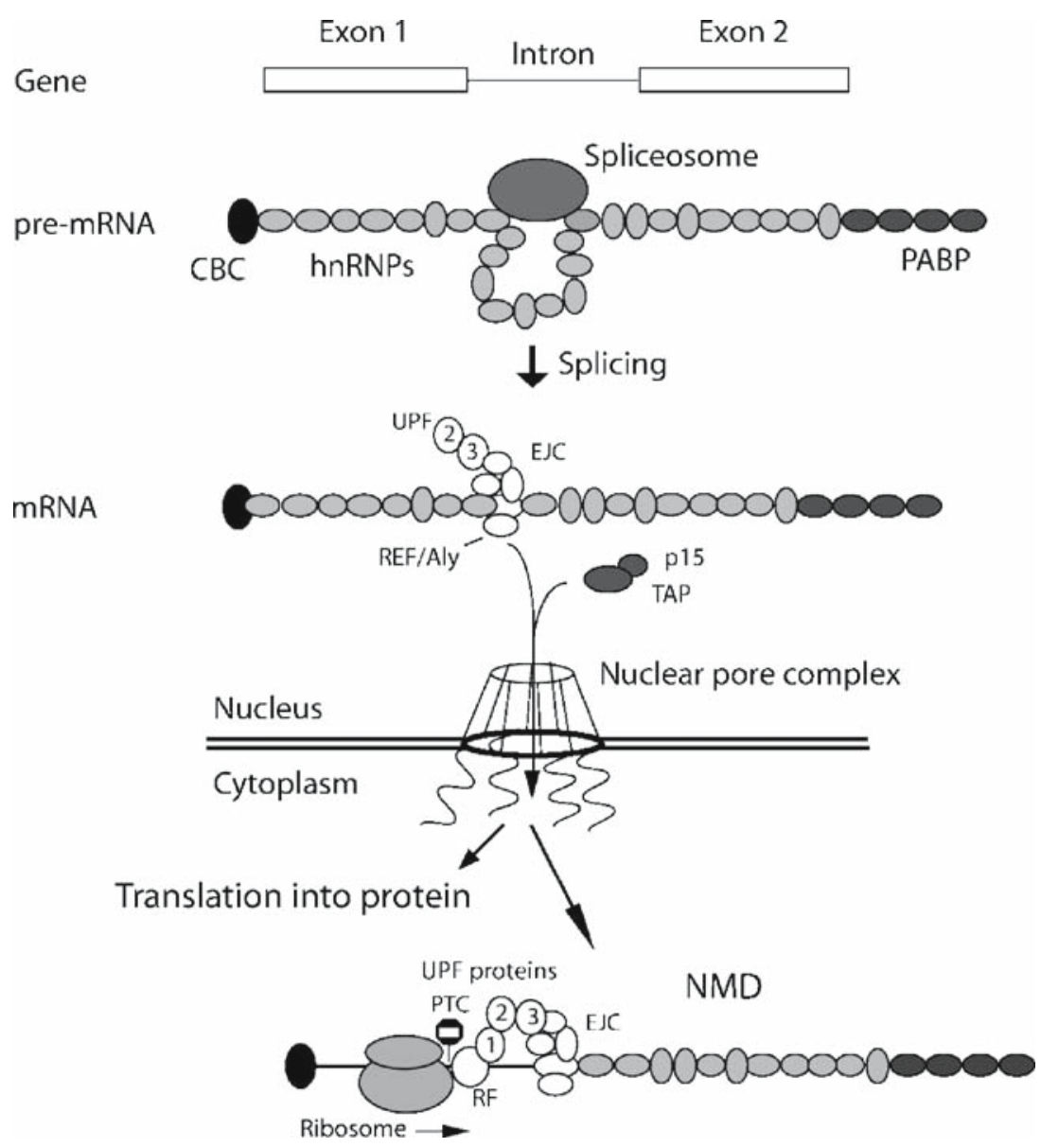

Fig. 3 mRNA biogenesis in mammalian cells-the exon junction complex links transcription, splicing, export, surveillance, translation and nonsense-mediated decay. As genes are transcribed, the pre-mRNAs are bound by hnRNP protein factors. After capping and polyadenylation, the cap and poly(A)+ tail are bound by the cap binding complex (CBC) and poly(A)-binding proteins $(\mathrm{PABP})$. Introns and splice sites are recognized co-transcriptionally. Intron removal by the spliceosome deposits the exon junction complex (EJC) circa 24 nt upstream of the exon-exon junction. The EJC contains around 20 proteins including the UPF proteins UPF3 (3) and UPF2 (2) and the export factor Aly/REF. The latter interacts with the export adaptor dimmer TAP/p15 which, in turn, interacts with the nuclear pore complex, allowing the mRNP to be exported. Once exported, mRNAs are translated into proteins by ribosomes. If the mRNA contains a premature termination codon (PTC), pausing of the ribosome recruits a complex containing release factors (RF) and UPF1 (1). Phosphorylation of UPF1 is a key step in targeting the aberrant transcript for degradation.

suggesting a role in mRNA surveillance and nonsense-mediated decay. This is supported by the localisation of the NMD proteins UPF2 and UPF3 in the nucleolus (Kim et al., unpublished). Thus the plant nucleolus may function in mRNA export, surveillance and NMD. 
Fig. 4 a-c mRNAs in the plant nucleolus. Distribution of the relative proportions of different classes of mRNAs from cDNA libraries of Arabidopsis whole cells, nuclei and nucleoli showing the decrease in fully spliced and increase in aberrantly spliced transcripts in the nucleolus. $S E$, single exon gene transcripts; $F S$, fully spliced transcripts; $A S$, aberrantly spliced transcripts. a Whole cell

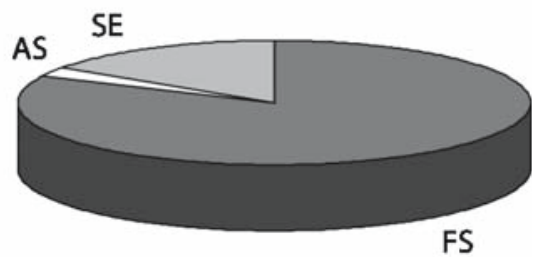

b Nucleus

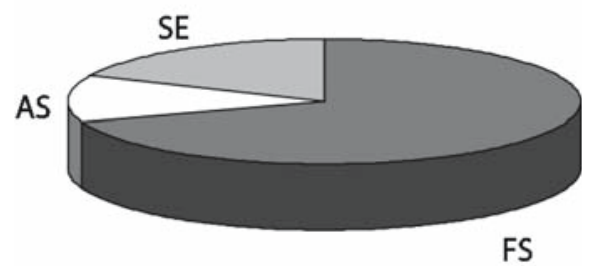

c Nucleolus

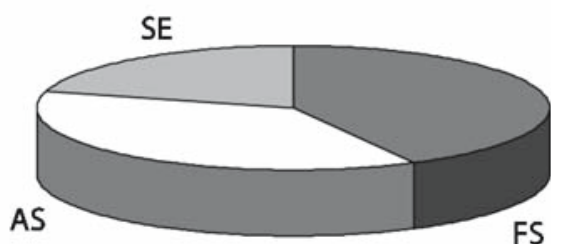

\section{A Role in mRNA Export?}

In eukaryotes, export of mRNPs from the nucleus to the cytoplasm is mediated by Aly/REF and UAP56 (Yra1p and Sub2p, respectively, in yeast) as part of the mRNP complex which interacts with the export receptor protein TAP (Mex67p in yeast) (see the chapter by V. Chinnusamy et al., this volume). This, in turn, interacts with components of the nuclear pore complex (Reed and Hurt 2002; Stutz and Izaurralde 2003; Aguilera 2005; Reed and Cheng 2005). In yeast, all three proteins (Mex67p, Yra1p and Sub2p) are required for export, but in Drosophila and Caenorhabiditis elegans Aly/REF is non-essential (Gatfield and Izaurralde 2002; Longmann et al. 2003; MacMorris et al. 2003). This may reflect the ability of arginine-serine-rich (SR) protein splicing factors to interact with TAP and act as alternative export adaptors (Reed and Cheng 2005). Little is known about mRNA export components and pathways in plants. In particular, it is not known whether Aly/REF or UAP56 is needed for mRNA export and only recently has a possible orthologue of TAP has been identified (Hernandez-Pinzon et al. 2007). Nevertheless, three of the four Arabidopsis Aly/REF proteins and UAP56 localise strongly to the nucleolus (Pendle et al. 2005) and both Arabidopsis and tobacco Aly proteins shuttle 
between the nucleolus/nucleus and cytoplasm (Uhrig et al. 2004; Canto et al. 2006). In addition, besides EJC proteins, some splicing factors (including SR proteins), spliceosomal snRNP proteins and hnRNP proteins were identified in the Arabidopsis nucleolar proteome (Pendle et al. 2005) and the Arabidopsis SR protein RSZ22 has recently been shown to shuttle between the nucleoplasm, nuclear speckles and the nucleolus (Tillemans et al. 2006). These observations are consistent with the involvement of the nucleolus with mRNA export.

The potential export of mRNAs via the nucleolus parallels studies of viral RNA export in mammals. The export of herpesvirus saimiri (HVS) mRNA involves the expression of the viral ORF57 protein which causes Aly, UAP56 and other human export factors to be redistributed to the nucleolus (Boyne and Whitehouse 2006). ORF57 is a nucleocytoplasmic shuttling protein which binds viral intronless mRNAs and, by interacting with Aly and the transcription/export complex (TREX), accesses TAP-mediated export (Williams et al. 2005). Nucleolar trafficking of ORF57 is essential for efficient export of the viral mRNAs (Boyne and Whitehouse 2006). Similarly, the human immunodeficiency virus type 1 (HIV-1) exports unspliced and singly spliced viral mRNAs via the nucleolus for replication (Michienzi et al. 2000; Hiscox 2007). The virus-encoded protein Rev is a nucleocytoplasmic shuttling protein which accumulates in the nucleolus. It interacts with the export factor CRM1 and particular nucleoporins, causing their relocalisation to the nucleolus. By binding a specific sequence in viral unspliced mRNAs and interacting with CRM1 and the nucleoporins, it is thought to assemble an export-competent complex in the nucleolus (Hope 1999). Thus these viral mRNAs are targeted to the nucleolus, where they associate with export factors and are exported. These pathways may represent an inherent eukaryotic nucleolar mRNA export pathway, which is exploited by these viruses. The importance of mRNA export in abiotic stress responses is reviewed in the chapter by V. Chinnusamy et al. (this volume).

\section{A Role in mRNA Surveillance and NMD?}

Eukaryotic systems utilise NMD as a quality-control mechanism to recognise and destroy transcripts containing PTCs (PTC+ transcripts) (Maquat 2004; Lejeune and Maquat 2005) preventing the formation of truncated polypeptides which could be potentially harmful for the cell by acting as dominant-negative mutations (see the chapter by D. A. Belostotsky, this volume). The NMD pathway has been widely studied in yeast, Caenorhabiditis elegans, Drosophila and humans and there are differences in components and mechanisms by which PTCs are discriminated (Culbertson and Leeds 2003; Conti and Izzuralde 2005). In mammals, PTC-containing transcripts have classically been thought to be targeted for NMD by the interaction of a paused ribosome at the PTC with a downstream EJC (Maquat 2004; Lejeune and Maquat 2005). However, recent results suggest that the distance between the termination codon and the poly(A) tail is a major determinant of NMD such that premature translation termination in the wrong mRNP context, possibly through interaction with poly(A)-binding proteins, triggers NMD (Bühler et al. 2006). 
An EJC downstream of a premature termination codon potentially acts as an enhancer of NMD in this model (Bühler et al. 2006). Thus the underlying mechanism of NMD in mammals may be more related to those of yeast and Caenorhabiditis elegans, which are EJC-independent and rely on the distance between the PTC and 3' UTR, although, in yeast, this may also involve specific sequences being recognised by trans-acting factors.

More than $90 \%$ of the aberrant transcripts found in plant nucleoli are putative NMD substrates based on NMD determinants in plants (Kim et al., unpublished; Kertész et al. 2006). The majority of reported examples of NMD in plants derive from intron-containing genes and, for the most part, the positions of PTCs and exon junctions would be consistent with an EJC-dependent or -enhanced effect. However, it is also clear that EJC-independent NMD occurs in plants with reduced mRNA stability dependent on the position of the PTC in PTC-containing intronless transcripts (Van Hoof and Green 2006). Recently, long 3' UTRs and introns in the 3' UTR were shown to trigger NMD in plants (Kertész et al. 2006). In terms of the protein components of plant NMD, orthologues of UPF1, UPF2 and UPF3 have been identified (Pendle et al. 2005; van Hoof and Green 2006). Arabidopsis gene orthologues of UPF1 and UPF3 have also been shown to function in NMD. UPF3 suppresses the levels of aberrantly spliced, PTC-containing transcripts (Hori and Watanabe, 2005), and Arabidopsis UPFl is indispensable (Arciga-Reyes et al. 2006) and causes decreased levels of mRNAs when tethered in different positions in mRNAs (Kertész et al. 2006). Thus the rapid degradation of PTC-containing transcripts from both intron-containing and intronless genes, and the overall conservation of EJC and NMD proteins (Pendle et al. 2005; Kertész et al. 2006; van Hoof and Green 2006), suggests that both EJC-dependent and EJC-independent mechanisms are utilised in plants. The link between the nucleolus and NMD in plants, seen with the presence of aberrant mRNAs in the nucleolus, is further reflected by the localisation of UPF2 and UPF3 to the nucleolus (Kim et al., unpublished). Other aspects of mRNA decay are covered in the chapter by D. A. Belostotsky.

\section{The Nucleolus as a Major Centre for RNA Metabolism and Regulation of Gene Expression}

Over the last 40 years and particularly in the last 10-15 years, the nucleolus has grown in importance as a highly dynamic centre of RNA metabolism and RNP assembly. It has the major function in ribosomal subunit assembly needed to supply the cell with ribosomes for translation, and is involved in the processing and assembly of many other RNAs and RNPs. Not surprisingly, therefore, the nucleolus is involved in the regulation of key cellular processes and responds to growth conditions and external stresses. The recent links to transcriptional silencing, mRNA export and NMD in plants not only add to the multiple functions of the nucleolus but also enhance the concept of a role for the nucleolus in co-ordinating different RNA metabolism pathways. 


\section{References}

Aguilera A (2005) Cotranscriptional mRNP assembly: from the DNA to the nuclear pore. Curr Opin Cell Biol 17:242-250

Ang LH, Chattopadhyay S, Wei N, Oyama T, Okada K, Batschauer A, Deng XW (1998) Molecular interaction between COP1 and HY5 defines a regulatory switch for light control of Arabidopsis development. Mol Cell 1:213-222

Andersen JS, Lyon CE, Fox AH, Leung AK, Lam YW, Steen H, Mann M, Lamond AI (2002) Directed proteomic analysis of the human nucleolus. Curr Biol 12:1-11

Andersen JS, Lam YW, Leung AK, Ogg SE, Lyon CE, Lamond AI, Mann M (2005) Nucleolar proteome dynamics. Nature 433:77-78

Andersen CBF, Ballut L, Johansen JS, Chamieh H, Nielsen KH, Oliveira CLP, Pedersen JS, Séraphin B, Le Hir H, Andersen GR (2006) Structure of the exon junction core complex with a trapped DEAD-box ATPase bound to RNA. Science 313:1968-1972

Arciga-Reyes L, Wootton L, Kieffer M, Davies B (2006) UPF1 is required for nonsense-mediated mRNA decay (NMD) and RNAi in Arabidopsis. Plant J 47:480-489

Barakat A, Szick-Miranda K, Chang L-F, Guyot R, Blanc G, Cooke R, Delseny M, Bailey-Serres J (2001) The organisation of cytoplasmic ribosomal protein genes in the Arabidopsis genome. Plant Physiol 127:398-415

Barneche F, Gaspin C, Guyot R, Echeverria M (2001) Identification of 66 box C/D snoRNAs in Arabidopsis thaliana: Extensive gene duplications generated multiple isoforms predicting new ribosomal RNA 2'-O-methylation sites. J Mol Biol 311:57-73

Bertrand E, Houser-Scott F, Kendall A, Singer RH, Engelke DR (1998) Nucleolar localization of early tRNA processing genes. Genes Dev 12:2463-2468

Beven AF, Lee R, Razaz M, Leader DJ, Brown JWS, Shaw PJ (1996) The organization of ribosomal RNA processing correlates with the distribution of nucleolar snRNAs. J Cell Sci 109:1241-1251

Beven AF, Simpson GG, Brown JWS, Shaw PJ (1995) The organization of spliceosomal components in the nuclei of higher plants. J Cell Sci 108:509-51

Bond VC, Wold B (1993) Nucleolar localisation of myc transcripts. Mol Cell Biol 13:3221-3230

Boyne JR, Whitehouse A (2006) Nucleolar trafficking is essential for nuclear export of intronless herpesvirus mRNA. Proc Natl Acad Sci USA 103:15190-15195

Boisvert F-M, van Koningsbruggen S, Navascués J, Lamond AI (2007) The multifunctional nucleolus. Nat Rev Mol Cell Biol 8:574-585

Boudonck K, Dolan L, Shaw PJ (1998) Coiled body numbers in the Arabidopsis root epidermis are regulated by cell type, developmental stage and cell cycle parameters. J Cell Sci 111:3687-3694

Boudonck K, Dolan L, Shaw PJ (1999) The movement of coiled bodies visualized in living plant cells by the green fluorescent protein. Mol Biol Cell 10:2297-2307

Brodsky AS, Silver PA (2000) Pre-mRNA processing factors are required for nuclear export. RNA 6:1737-1749

Brown JWS, Clark GP, Simpson, CG, Leader DJ, Lowe TM (2001) Multiple snoRNA gene clusters from Arabidopsis. RNA 7:5718-5732

Brown JWS, Echeverria M, Qu L-H (2003) Plant snoRNAs: functional evolution and new modes of gene expression. Trends Plant Sci 8:42-49

Brown JWS, Shaw PJ (1998) Small nucleolar RNAs and pre-rRNA processing in plants. Plant Cell 10:649-657

Bühler M, Steiner S, Mohn F, Paillusson A, Mühlemann O (2006) EJC-independent degradation of nonsense immunoglobulin- $\mu$ mRNA depends on $3^{\prime}$ UTR length. Nat Struct Mol Biol 13:462-464

Canto T, Uhrig JF, Swanson M, Wright KM, MacFarlane SA (2006) Translocation of Tomato Bushy Stunt Virus p19 protein into the nucleus by ALY proteins compromises its silencing suppressor activity. J Virol 80:9064-9072 
Carneiro T, Carvalho C, Braga J, Rino J, Milligan L, Tollervey D, Carmo-Fonseca M (2007) Depletion of the yeast nuclear exosome subunit Rrp6 results in accumulation of polyadenylated RNAs in a discrete domain within the nucleolus. Mol Cell Biol 27:4157-4165

Cech TR (2004) Beginning to understand the end of the chromosome. Cell 116:273-279

Chen M, Schwab R, Chory J (2003) Characterization of the requirements for localization of phytochrome B to nuclear bodies. Proc Natl Acad Sci USA 100:14493-14498

Cheutin T, Misteli T, Dundr M (2004) Dynamics of nucleolar components. In: The Nucleolus (ed. Olsen, M.O.J.) Landes, Georgetown, USA/Kluwer, New York, USA. pp 29-40

Cioce M, Lamond AI (2005) Cajal bodies: a long history of discovery. Annu Rev Cell Dev Biol 21:105-131

Collier S, Pendle A, Boudonck K, van Rij T, Dolan L, Shaw PJ (2006) A distant coilin homologue is required for the formation of Cajal bodies in Arabidopsis. Mol Biol Cell 17:2942-2951

Conti E, Izzuralde E (2005) Nonsense-mediated decay: molecular insights and mechanistic variations across species. Curr Opin Cell Biol 17:316-325

Culbertson MR, Leeds PF (2003) Looking at mRNA decay pathways through the window of molecular evolution. Curr Opin Genet Dev 13:207-214

Custódio N, Carvalho C, Condado I, Antoniou M, Blencowe BJ, Carmo-Fonseca M (2004) In vivo recruitment of exon junction complex proteins to transcription sites in mammalian cell nuclei. RNA 10:622-633

Darzacq X, Jády BE, Verheggen C, Kiss AM, Bertrand E, Kiss T (2002) Cajal body-specific small nuclear RNAs: a novel class of 2'-O-methylation and pseudouridylation guide RNAs. EMBO J 21:2746-2756

Decatur WA, Fournier MJ (2002) rRNA modifications and ribosome function. Trends Biochem. Sci 7:344-351

Dove BK, You JH, Reed ML, Emmett SR, Brooks G, Hiscox JA (2006) Changes in nucleolar morphology and proteins during infection with the corona virus infectious bronchitis virus. Cell Microbiol 8:1147-1157

Dragon F, Gallagher JE, Compangnone-Post PA, Mitchell BM, Porwancher KA, Wehner KA, Wormsley S, Settlage RE, Shabanowitz J, Osheim Y, Beyer AL, Hunt DF, Baserga SJ (2002) A large nucleolar U3 ribonucleoprotein required for $18 \mathrm{~S}$ ribosomal RNA biogenesis. Nature 417:967-970

Etheridge KT, Banik SS, Armbruster B N, Zhu Y, Terns RM, Terns MP, Counter CM (2002) The nucleolar localisation domain of of the catalytic subunit of human telomerase. J Biol Chem 277:24764-24770

Fatica A, Tollervey D (2002) Making ribosomes. Curr Opin Cell Biol 14:313-318

Frey MR, Matera AG (1995) Coiled bodies contain U7 small nuclear RNA and associate with specific DNA sequences in interphase human cells. Proc Natl Acad Sci USA 92:5915-5919

Gallagher JE, Dunbar DA, Grannemann S, Mitchell BM, Osheim Y, Beyer AL, Baserga SJ (2004) RNA polymerase I transcription and pre-rRNA processing are linked by specific SSU processosome components. Genes Dev 18:2506-2517

Ganot P, Jady BE, Bortolin ML, Darzacq X, Kiss T (1999) Nucleolar factors direct the 2'-O-ribose methylation and pseudouridylation of U6 spliceosomal RNA. Mol Cell Biol 19:6909-6917

Gatfield D, Izurralde E (2002) REF1/Aly and the additional exon junction complex proteins are dispensible for nuclear mRNA export. J Cell Biol 159:579-588

Gerbi SA, Lange TS (2002) All small nuclear RNAs (snRNAs) of the [U4/U6.U5] tri-snRNP localize to nucleoli; Identification of the nucleolar localization element of U6 snRNA. Mol Biol Cell 13:3123-3137

Gonzalez-Melendi P, Wellis B, Beven AF, Shaw PJ (2001) Single ribosomal transcription units are linear, compacted Christmas trees in plant nucleoli. Plant J 27:223-233

Gorski, SA, Dundr M, Misteli T (2006) The road much travelled: trafficking in the cell nucleus. Curr Opin Cell Biol 18:284-290

Grandi P, Rybin V, Bassker J, Petfalski E, Strauss D, Marzioch M, Schafer T, Kuster B, Tschochner H, Tollervey D, Gavin A-C, Hurt E (2002) 90S pre-ribosomes include the 35S pre-rRNA, the U3 
snoRNP, and 40S subunit processing factors but predominantly lack $60 \mathrm{~S}$ synthesis factors. Mol Cell 10:105-115

Grannemann S, Baserga SJ (2004) Ribosome biogenesis: of knobs and RNA processing. Exp Cell Res 296:43-50

Grannemann S, Baserga SJ (2005) Crosstalk in gene expression: coupling and co-regulation of rDNA transcription, pre-ribosome assembly and pre-rRNA processing. Curr Opin Cell Biol 17:281-286

Grosshans H, Deinart K, Hurt E, Simos G (2001) Biogenesis of the signal recognition particle (SRP) involves import of SRP proteins into the nucleolus, assembly with SRP-RNA, and Xpo1p-mediated export. J Cell Biol 153:745-762

Han MH, Goud S, Song L, Fedoroff N (2004) The Arabidopsis double-stranded RNA-binding protein HYL1 plays a role in microRNA-mediated gene regulation. Proc Natl Acad Sci USA 101:1093-1098

Handwerger KE, Gall JG (2006) Subnuclear organelles: new insights into form and function. Trends Cell Biol 16:19-26

Hernandez-Pinzon I, Yelina NE, Schwach F, Studholme DJ, Baulcombe D, Dalmay T (2007) SDE5, the putative homologue of a human mRNA export factor, is required for transgene silencing and accumulation of trans-acting endogenous siRNA. Plant J 50:140-148

Hiscox JA (2002) The nucleolus-a gateway to viral infection? Arch Virol 147:1077-1089

Hiscox JA (2007) RNA viruses: hijacking the dynamic nucleolus. Nat Rev Microbiol 5:119-127

Hope TJ (1999) The ins and outs of HIV. Rev Arch Biochem Biophys 365:186-191

Hopper AK, Phizicky EM (2003) tRNA transfers to the limelight. Genes Dev 17:162-180

Hori K, Watanabe Y (2005) UPF3 suppresses aberrant spliced mRNA in Arabidopsis. Plant J 43:530-540

Ideue T, Azad AK, Yoshida J, Matsusaka T, Yanagida M, Ohshima Y, Tani T (2004) The nucleolus is involved in mRNA export from the nucleus in fission yeast. J Cell Sci 117:2887-2895

Jacobson MR, Cao LG, Taneja K, Singer RH, Wang YL, Pederson T (1997) Nuclear domains of RNA subunit of RNase P. J Cell Sci 110:829-837

Jacobsen MR, Pederson T (1998) Localization of signal recognition particle RNA in the nucleolus of mammalian cells. Proc Natl Acad Sci USA 95:7981-7986

Jady BE, Darzacq X, Tucker KE, Matera AG, Bertrand E, Kiss T (2003) Modification of Sm small nuclear RNAs occurs in the nucleoplasmic Cajal body following import from the cytoplasm. EMBO J 22:1878-1888

Jady BE, Bertrand E, Kiss T (2004) Human telomerase RNA and box H/ACA scaRNAs share a common Cajal body-specific localization signal. J Cell Biol 164:647-652

Jarrous N, Wolenski JS, Wesolowski D, Lee C, Altmann S (1999) Localisation in the nucleolus and coiled bodies of protein subunits of the ribonucleoprotein ribonuclease P. J Cell Biol 146:559-572

Kadowaki T, Schneiter R, Hitomi M, Tartakoff AM (1995) Mutations in nucleolar proteins lead to nucleolar accumulation of poly(A)+RNA in Saccharomyces cerevisiae. Mol Biol Cell 6:1103-1110

Kertész S, Keréyi Z, Mérai Z, Bartos I, Palfy T, Barta E, Silhavy D (2006) Both introns and long $3^{\prime}$-UTRs operate as cis-acting elements to trigger nonsense-mediated decay in plants. Nucl Acids Res 34:6147-6157

Kim SH, Ryabov EV, Kalinina NO, Rakitina DV, Gillespie T, Haupt S, MacFarlane S, Brown JWS, Taliansky M (2007a) Cajal bodies, the nucleolus and fibrillarin are required for a plant virus systemic infection. EMBO J 26:2169-2179

Kim SH, MacFarlane S, Kalinina NO, Rakitina DV, Ryabov EV, Gillespie T, Haupt S, Brown JWS, Taliansky M (2007b) Interaction of a plant virus-encoded protein with the major nucleolar protein fibrillarin is required for systemic virus infection. Proc Natl Acad Sci USA 104:11115-11120

Kircher S, Gil P, Kozma-Bogna L, Fejes E, Speth V, Husselstein-Muller T, Bauer D, Adam E, Schafer E, Nagy F (2002) Nucleocytoplasmic partitioning of the plant photoreceptors phytochrome A, B, C, D, and E is regulated differentially by light and exhibits a diurnal rhythm. Plant Cell 14:1541-1555 
Kiss T (2002) Small nucleolar RNAs: An abundant group of non-coding RNAs with diverse cellular functions. Cell 109:145-148

Lange TS, Gerbi SA (2000) Transient nucleolar localization of U6 small nuclear RNA in Xenopиs laevis oocytes. Mol Biol Cell 11:2419-2428

Lamond AI, Spector DL (2003) Nuclear speckles: a model for nuclear organelles. Nat Rev Mol Cell Biol 4:605-612

Lejeune F, Maquat LE (2005) Mechanistic links between nonsense-mediated mRNA decay and pre-mRNA splicing in mammalian cells. Curr Opin Cell Biol 17:309-315

Leung AK, Lamond AI (2003) The dynamics of the nucleolus. Crit Rev Eukaryot Gene Expr 13:39-54

Leung AKL, Gerlich D, Miller G, Lyon CE, Lam YW, Lleres D, Daigle N, Zomerdijk J, Ellenberg J, Lamond AI (2004) Quantitative kinetic analysis of nucleolar breakdown and reassembly during mitosis in live human cells. J Cell Biol 166:787-800

Leung AK, Trinkle-Mulcahy L, Lam YW, Andersen JS, Mann M Lamond AI (2006) NoPdb: Nucleolar Proteome Database Nucleic Acids Res. 34:218-20

Li CF, Pontes O, El-Shami M, Henderson IR, Bernatavichute YV, Chan SW-L, Lagrange T, Pikaard CS, Jacobsen SE (2006) An ARGONAUTE4-containing nuclear processing center colocalized with Cajal bodies in Arabidopsis thaliana. Cell 126:93-106

Li J, Kinoshita T, Pandey S, Ng CK, Gygi SP, Shimazaki K, Assmann SM (2002) Modulation of an RNA-binding protein by abscisic-acid-activated protein kinase. Nature 418:793-797

Longman D, Johnstone JL, Cáceres JF (2003) The Ref/Aly proteins are dispensable for mRNA export and development in Caenorhabditis elegans. RNA 9:881-891

Lorković ZJ, Hilscher J, Barta A (2004) Use of fluorescent protein tags to study nuclear organisation of the spliceosomal machinery in transiently transformed living plant cells. Mol Biol Cell 15:3233-3243

Lukowiak AA, Narayanan A, Li ZH, Terns RM, Terns MP (2001) The snoRNA domain of vertebrate telomerase RNA functions to localize the RNA within the nucleus. RNA 7:1833-1844

MacMorris M, Brocker C, Blumenthal T (2003) UAP56 levels affect viability and mRNA export in Caenorhabditis elegans. RNA 9:847-857

Maquat LE (2004) Nonsense-mediated mRNA decay: splicing, translation and mRNA dynamics. Nat Rev Mol Cell Biol 5:89-99

Marker C, Zemann A, Terhorst T, Kiefmann M, Kastenmayer JP, Green P, Bachellerie JP, Brosius J, Huttenhofer A (2002) Experimental RNomics: identification of 140 candidates for small non-messenger RNAs in the plant Arabidopsis thaliana. Curr Biol 12:2002-2013

Maser RS, DePinho RA (2002) Connecting chromosomes, crisis and cancer. Science 297:565-569

Matera AG (1999) Nuclear bodies: multifaceted subdomains of the interchromatin space. Trends Cell Biol 19:302-309

Michienzi A, Cagnon L, Bahner I, Rossi JJ (2000) Ribozyme-mediated inhibition of HIV 1 suggests nucleolar trafficking of HIV-1 RNA. Proc Natl Acad Sci USA 97:8955-8960

Miller OLJ, Beatty RR (1969) Visualisation of nucleolar genes. Science 164:955-957

Misteli T (2005) Concepts in nuclear architecture. BioEssays 27:477-487

Mitchell JR, Cheng J, Collins K (1999a) A box H/ACA small nucleolar RNA-like domain at the human telomerase RNA 3' end. Mol Cell Biol 19:567-576

Mitchell JR, Collins K (2000) Human telomerase activation requires two independent interactions between telomerase RNA and telomerase reverse transcriptase. Mol Cell 6:361-371

Mosgoeller W (2004) Nucleolar ultrastructure in vertebrates. In: The Nucleolus (ed. Olsen, M.O.J.) Landes, Georgetown, USA/Kluwer, New York, USA. pp 10-19

Narayanan A, Speckmann W, Terns R, Terns MP (1999) Role of the box C/D motif in localization of small nucleolar RNAs to coiled bodies and nucleoli. Mol Biol Cell 10:2131-2147

Olsen MOJ, Dundr M, Szebeni A (2000) The nucleolus: an old factory with unexpected capabilities. Trends Cell Biol 10:189-196

Olsen MOJ (2004) Non-traditional roles of the nucleolus. In: The Nucleolus (ed. Olsen, M.O.J.) Landes, Georgetown, USA/Kluwer, New York, USA. pp 329-342

Palacios I M, Gatfield G, St. Johnston D, Izaurralde E (2004) An eiF4AIII-containiung complex required for mRNA localization and nonsense-mediated decay. Nature 427:753-757 
Pederson T (1998) The plurifunctional nucleolus. Nucl Acids Res 26:3871-3876

Pendle AF, Clark GP, Boon R, Lewandowska D, Lam YW, Andersen J, Mann M, Lamond AI, Brown JWS, Shaw PJ (2005) Proteomic analysis of the Arabidopsis nucleolus suggests novel nucleolar functions. Mol Biol Cell 16:260-269

Pillai RS, Will CL, Luhrmann R, Schumerli D, Muller B (2001) Purified U7 snRNPs lack the Sm proteins D1 andD2 but contain Lsm10, a new $14 \mathrm{kDa}$ Sm D1-like protein. EMBO J 20:5470-5479

Politz JC, Polena I, Trask I, Bazett-Jones DP, Pederson T (2005) A nonribosomal landscape in the nucleolus revealed by the stem cell protein nucleostemin. Mol Biol Cell 16:3401-3410

Pontes O, Li CF, Nunes PC, Haag J, Ream T, Vitins A, Jacobsen SE, Pikaard CS (2006) The Arabidopsis chromatin-modifying nuclear siRNA pathway involves a nucleolar RNA processing center. Cell 126:79-92

Pontvianne F, Matia I, Douet J, Tourmente S, Medina FJ, Echeverria M, Saez-Vasquez J (2007) Characterization of AtNUC-L1 reveals a central role of nucleolin in nucleolus organization and silencing of AtNUC-L2 gene in Arabidopsis. Mol Biol Cell 18:369-379

Qu LH, Meng Q, Zhou L, Chen Y-Q (2001) Identification of 10 novel snoRNA gene clusters from Arabidopsis thaliana. Nucl Acids Res 29:1623-1630

Reed R, Hurt E (2002) A conserved mRNA export machinery coupled to pre-mRNA splicing. Cell 108:523-531

Reed R, Cheng H (2005) TREX, SR proteins and export of mRNA. Curr Opin Cell Biol 17:269-273

Raška I, Shaw PJ, Cmarko D (2006) Structure and function of the nucleolus in the spotlight. Curr Opin Cell Biol 18:325-334

Rubbi CP, Milner J (2003) Disruption of the nucleolus mediates stabilisation of p53 in response to DNA damage and other stresses. EMBO J 22:6068-6077

Saez-Vasquez J, Caparros-Ruiz D, Barneche F, Echeverria M (2004) A plant snoRNP complex containing snoRNAs, fibrillarin and nucleolin-like proteins is competent for both rRNA gene binding and pre-rRNA processing in vitro. Mol Cell Biol 24:7284-7297

Scherl A, Couté Y, Déon C, Callé A, Kindbeiter K, Sanchez J-C, Greco A, Hochstrasse D, Diaz J-J (2002) Functional proteomics analysis of human nucleolus. Mol Biol Cell 13:4100-4109

Schafer T, Strauss D, Petfalski E, Tollervey D, Hurt E (2003) The path from nucleolar 90S to cytoplasmic 40S pre-ribosomes. EMBO J 22:1370-1380

Schneiter R, Kadowaki T, Tartakoff AM (1995) mRNA transport in yeast: time to reinvestigate the functions of the nucleolus. Mol Biol Cell 6:357-370

Shaw PJ, Brown JWS (2004) Plant nuclear bodies. Curr Opin Plant Biol 7:614-620

Shaw PJ, Jordan EG (1995) The nucleolus. Annu Rev Cell Dev Biol 11:93

Shaw PJ, Beven AF, Leader DJ, Brown JWS (1998) Localization and processing from a polycistronic precursor of novel snoRNAs in maize. J Cell Sci 111:2121-2128

Sleeman JE, Lamond AI (1999) Newly assembled snRNPs associate with coiled bodies before speckles, suggesting a nuclear snRNP maturation pathway. Curr Biol 9:1065-1074

Song L, Han MH, Lesicka J, Fedoroff NV (2007) Arabidopsis primary microRNA processing proteins HYL1 and DCL1 define a nuclear body distinct from the Cajal body Proc Natl Acad Sci USA 104:5437-5442

Steiner-Mosonyi M, Mangroo D (2004) The nuclear tRNA aminoacylation-dependent pathway may be the principal route used to export tRNA from the nucleus in Saccharomyces cerevisiae. Biochem J 378:809-816

Stutz F, Izaurralde E (2003) The interplay of nuclear mRNP assembly, mRNA surveillance and export. Trends Cell Biol 13:319-327

Tange TO, Nott A Moore MJ (2004) The ever-increasing complexities of the exon junction complex. Curr Opin Cell Biol 16:279-284

Tani T, Derby RJ, Hiraoka Y, Spector DL (1995) Nucleolar accumulation of poly(A)+RNA in heat-shocked yeast cells: implication of nucleolar involvement in mRNA transport. Mol Biol Cell 6:1515-1534

Tate WP, Poole ES (2004) My favorite organelle: The ribosome: lifting the veil from a fascinating organelle. Bioessays 26:582-588 
Tillemans V, Leponce I, Rausin G, Dispa L, Motte P (2006) Insights into nuclear organisation in plants as revealed by the dynamic distribution of Arabidopsis SR splicing factors. Plant Cell 18:3218-3234

Uhrig JF, Canto T, Marshall DF, MacFarlane SA (2004) Relocalisation of nuclear ALY proteins to the cytoplasm by the Tomato Bushy Stunt Virus p19 pathogenicity protein. Plant Physiol 135:2411-2423

van Hoof A, Green PJ (2006) NMD in plants. NMD in plants. In Nonsense-mediated mRNA decay, L. Maquat, ed. (Landes Bioscience, USA)

Venema J, Tollervey D (1999) Ribosome synthesis in Saccharomyces cerevisiae. Annu Rev Genet 33:261-311

Wong JM, Kusdra L, Collins K (2002) Subnuclear shuttling of human telomerase induced by transformation and DNA damage. Nat Cell Biol 4:731-736

Walter P, Johnson AE (1994) Signal sequence recognition and protein targeting to the endoplasmic reticulum membrane. Annu Rev Cell Biol 10:87-119

Williams BJL, Boyne JR, Goodwin DJ, Roaden L, Hautbergue GM,Wilson SA, Whitehouse A (2005) The prototype gamma-2 herpesvirus nucleocytoplasmic shuttling protein, ORF 57, transports viral RNA through the cellular mRNA export pathway. Biochem J 387:295-308

Yamaguchi R, Nakamura M, Mochizuki N, Kay SA, Nagatani A (1999) Light-dependent translocation of a phytochrome B-GFP fusion protein to the nucleus in transgenic Arabidopsis. J Cell Biol 145:437-445

Yu YT, Shu MD, Narayanan A, Terns RM, Terns MP, Steitz JA (2001) Internal modification of U2 small nuclear (sn)RNA occurs in nucleoli of Xenopus oocytes. J Cell Biol 152:1279-1288

Zhu Y, Tomlinson, RL, Lukowiak AA, Terns RM, Terns MP (2004) Telomerase RNA accumulates in Cajal bodies in human cancer cells. Mol Biol Cell 15:81-90 